\title{
TRICUSPID INCOMPETENCE FOLLOWING SUCCESSFUL MITRAL VALVOTOMY
}

\author{
BY \\ PATRICK MOUNSEY \\ From the Cardiac Department of the London Hospital \\ Received March 6, 1958
}

A rare, but important, complication of mitral valvotomy for mitral stenosis is the development of tricuspid incompetence (Mounsey, 1957). The syndrome may be defined as permanent tricuspid incompetence, coming on in the immediate post-operative period, after a successful mitral valvotomy, without any obvious cause for sudden right heart failure, in a patient who had never had tricuspid incompetence before operation, or in whom it had been transient or of slight degree. In this paper an account is given of the syndrome, with a discussion of its mechanism, treatment, and prognosis.

\section{The INVESTIGATION DesCRIBED}

Eight out of 260 patients developed tricuspid incompetence after mitral valvotomy performed for mitral stenosis in this hospital during the past seven years by either Mr. Vernon Thompson or Mr. Geoffrey Flavell. They were also under the care of the Cardiac Department before and after operation.

The patients were all women and their ages varied between 25 and 45 at the time of operation, the average age being 38 years.

With one exception, all the patients had tight mitral stenosis at operation, the valve measuring about $1 \mathrm{~cm}$. in its long diameter: in the eighth patient the valve measured $2 \mathrm{~cm}$. All had a successful mitral valvotomy, the valve diameter length being increased to between 3.5 and $4.0 \mathrm{~cm}$. in two, between 2.5 and $3.0 \mathrm{~cm}$. in five; and only in one was the final diameter after operation as small as $2.5 \mathrm{~cm}$.

In no patient was there intractable right heart failure before operation. Three of the patients gave no history of right heart failure, three had been in failure once shortly before operation, and in two only was there a clear history of more than one attack of failure.

Pulmonary hypertension, judged on clinical, electrocardiographic, and radiological evidence, was present in three patients. The pulmonary arterial pressure was considerably raised in two and moderately raised in one, in whom it measured $44 / 15 \mathrm{~mm}$. $\mathrm{Hg}$, with a pulmonary vascular resistance of 6 units. The remaining five had no clinical evidence of pulmonary hypertension.

Recurrent attacks of severe bronchitis were a feature in only two patients. Two others had an associated aortic valve lesion, but the slight aortic regurgitation present was not sufficiently severe to influence the progress after operation. Five of the eight were in atrial fibrillation before operation.

The general heart size before operation in this group was within that of the average range of patients selected for mitral valvotomy in this hospital (Mounsey, 1957). Five patients showed moderate and one slight enlargement. Only two showed considerable enlargement, but this was 
largely due to a dilated right atrium and with the exception of these two who had slight tricuspid incompetence before operation, none had enlargement of the right atrium before operation.

The electrocardiogram showed evidence of considerable right ventricular preponderance in two patients and moderate preponderance in the third, the figures for whose pressures at catheterization have already been given. Of the three in sinus rhythm before operation, two merely showed bifid $\mathbf{P}$ waves of the type commonly seen in mitral stenosis, with, in addition in one, prolongation of the $\mathbf{P}-\mathbf{R}$ interval to 0.3 seconds. One, however, showed tall spiked right heart $P$ waves, which were thought later to be evidence of tricuspid stenosis.

Slight pre-existing tricuspid incompetence was seen in two patients. Both showed enlargement of the right atrium before operation (Fig. 1). In one patient a $c v$ wave in the jugular venous pulse

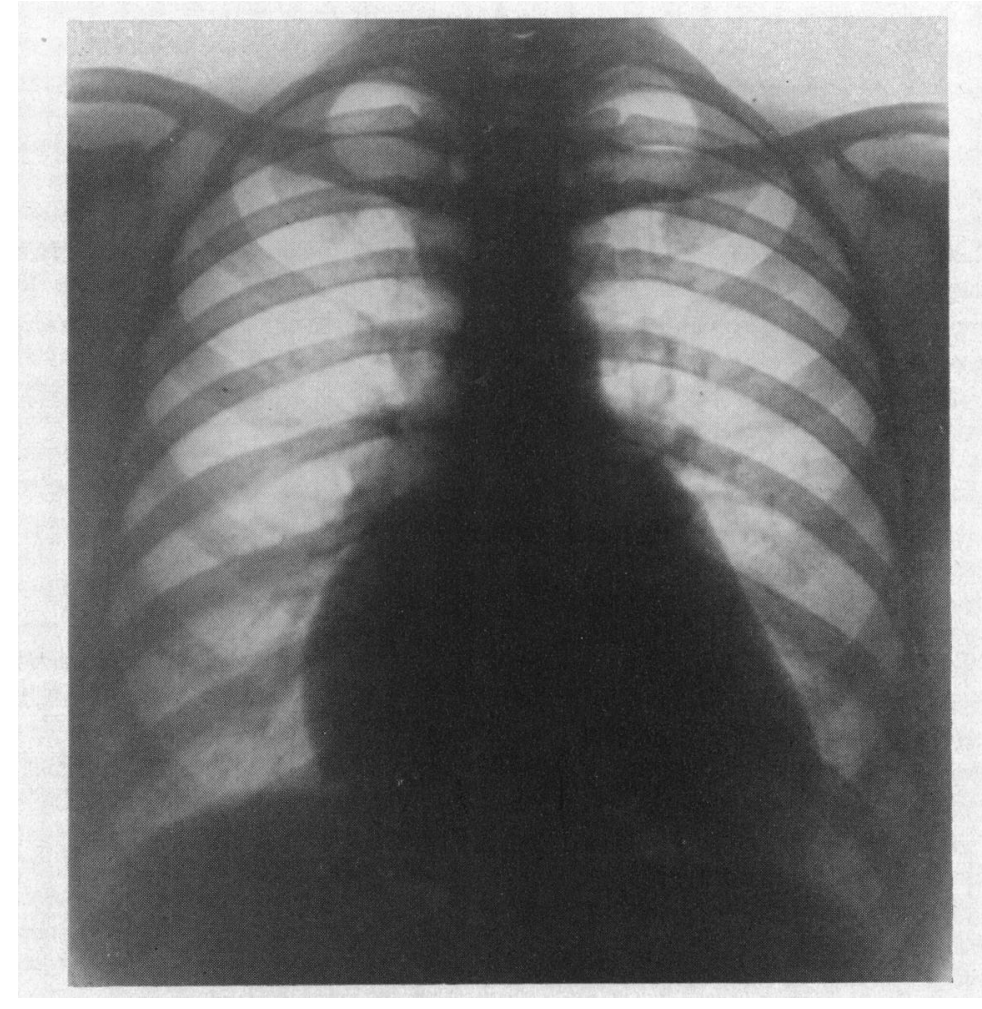

Fig. 1.-Postero-anterior radiogram of the chest before mitral valvotomy. Marked enlargement of the right atrium. Signs of tricuspid incompetence slight before, and greater after, valvotomy.

was seen at one attendance only in the Out-patient Department, and had subsided when she was next seen. In the other the $c v$ wave was brought out on exertion, but subsided with rest.

Tricuspid stenosis of slight degree was probably present in one patient before operation, on the evidence of tall peaked right heart $\mathbf{P}$ waves in the electrocardiogram without right ventricular preponderance (Fig. 2). The jugular venous pressure was slightly raised, although the $a$ waves were not very large. Cardiac catheterization was not carried out on this patient.

\section{The Diagnosis of Tricuspid InCOMPETENCE}

Tricuspid incompetence was diagnosed on clinical grounds and no patient was examined after operation by cardiac catheterization or by dye dilution techniques. The clinical criteria were a 
positive $c v$ wave seen on inspection of the jugular venous pulse (Fig. 3); enlargement of the liver with systolic pulsation; right atrial enlargement in the radiogram (Fig. 1); and a systolic murmur loudest at the lower sternal area. Least emphasis was placed on the systolic murmur, since in patients with a very severe degree of incompetence the murmur is sometimes trivial or absent. Deep inspiration usually served to accentuate the $c v$ wave in the jugular venous pulse and the pulsation in the liver, and to increase the loudness of the murmur.

There were two other clinical signs, which were not constant, but were noticeable in some patients. First, a right ventricular heave due to increased right ventricular stroke output, consequent on the backward flow through the incompetent valve. Secondly, a right ventricular diastolic thrust, due to the surge of blood in early diastole from the right atrium into the ventricle, because of the high

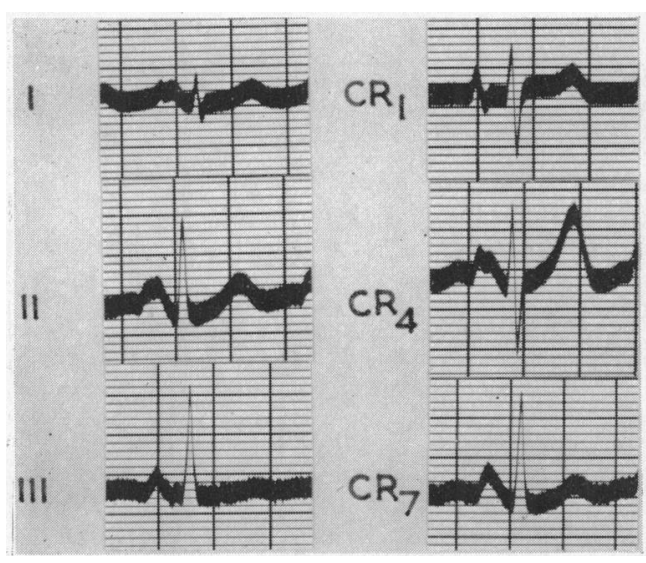

Fig. 2.-Electrocardiogram before mitral valvotomy. Tall peaked right atrial $\mathbf{P}$ waves, without right ventricular preponderance.
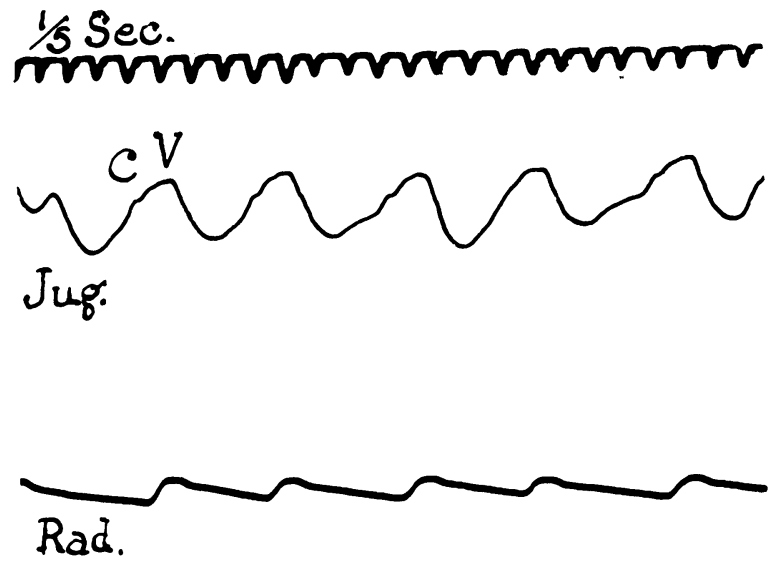

FIG. 3.-Jugular and radial pulse records on Mackenzie polygraph, showing $c v$ wave in jugular venous pulse.

right atrial pressure at the end of systole in tricuspid incompetence (Mounsey, 1957). This thrust was accompanied by the descent of the $v$ wave in the jugular venous pulse, and sometimes also by an early diastolic murmur (Müller and Shillingford, 1954).

\section{The Clinical Syndrome of Post-Operative Tricuspid Incompetence}

The onset of tricuspid incompetence after mitral valvotomy was insidious, and there were usually no accompanying subjective symptoms.

In five of the eight patients tricuspid incompetence developed about the fourteenth post-operative day. In the other three, the date of onset was uncertain, but it was first noticed two months after operation in two, and one year after in the other.

The degree of incompetence varied: in six patients it was considerable, the systolic $c v$ wave in the jugular venous pulse reaching the angle of the jaw: in the other two it was slight and only clearly seen in the jugular pulse after exertion, when the $c v$ wave was 5 to $7 \mathrm{~cm}$. above the sternal angle, with the patient laying at $45^{\circ}$. In all patients the liver was enlarged, being four fingers' breadth below the costal margin in the two affected most severely, two to three fingers' breadth in the intermediate group, and just palpable in the two with the mildest degree. Systolic pulsation of the liver was noted in every patient, of a degree parallel with the height of the $c v$ wave in the jugular venous pulse.

Increase in size of the right atrium following mitral valvotomy was seen in six patients. This was assessed in a postero-anterior radiogram: it was usually obvious six weeks after operation, when the pleural and pericardial effusions had absorbed, and did not appear to enlarge further in the :subsequent follow-up period. The degree of enlargement varied: in three patients it was considerable 


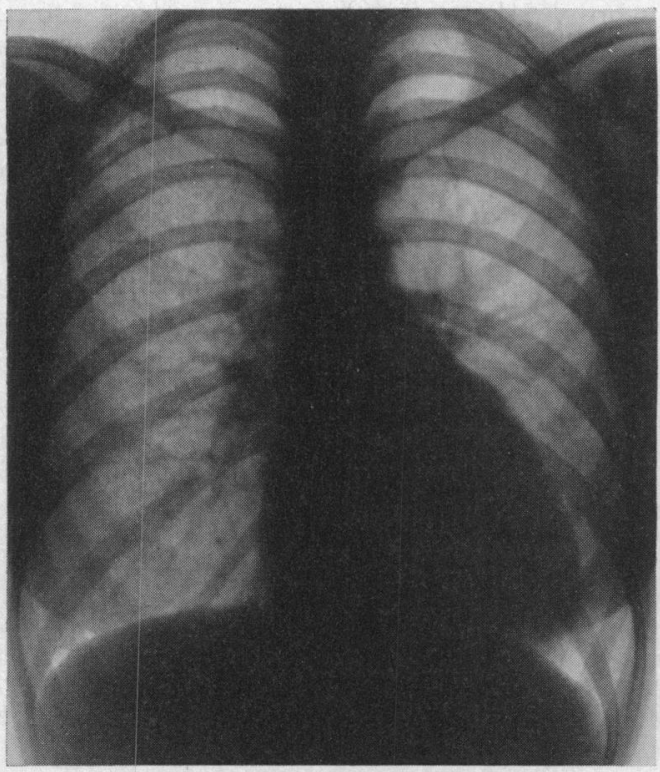

A

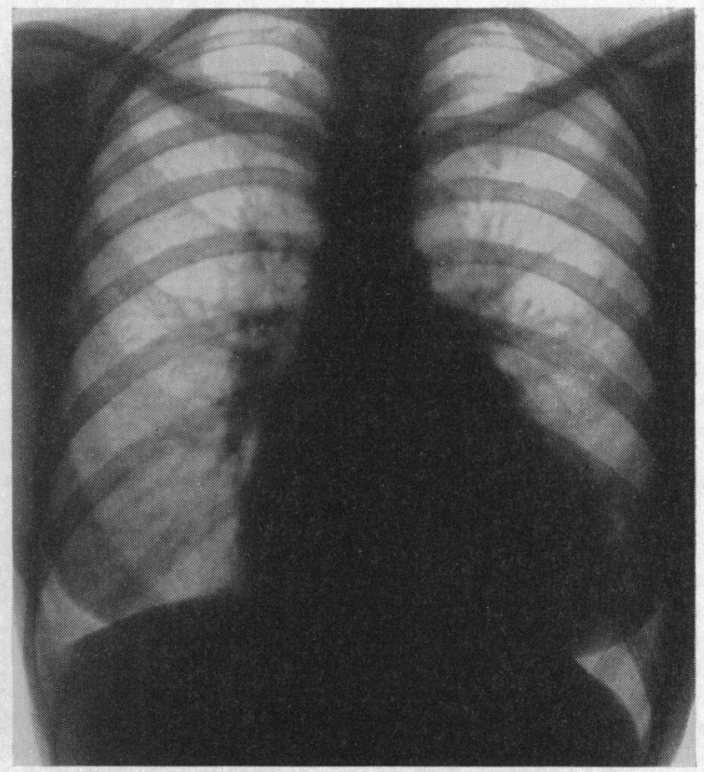

B

FIG. 4.-Postero-anterior radiogram of the same patient, (A) before, and (B) after, mitral valvotomy. Moderate enlargement of the right atrium after valvotomy.

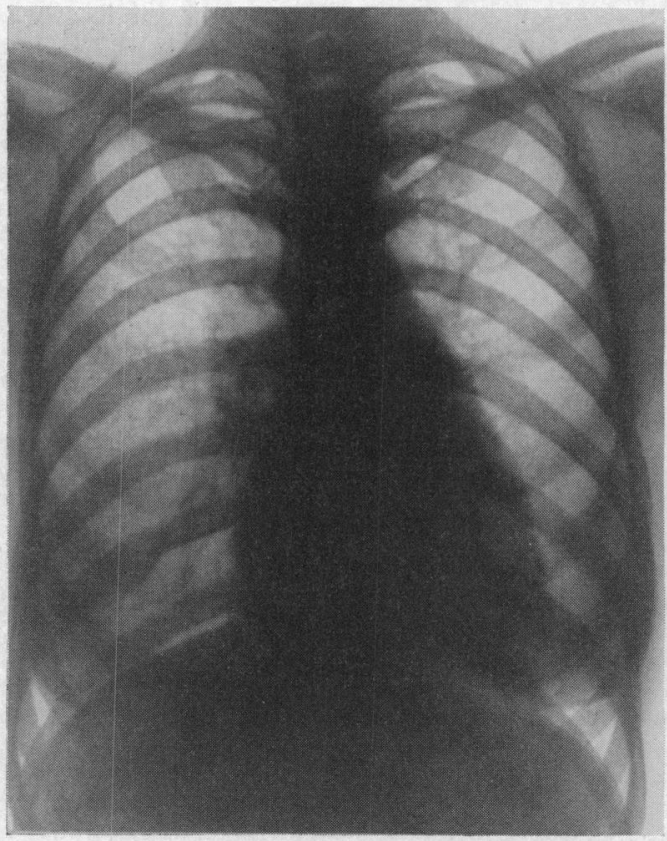

A

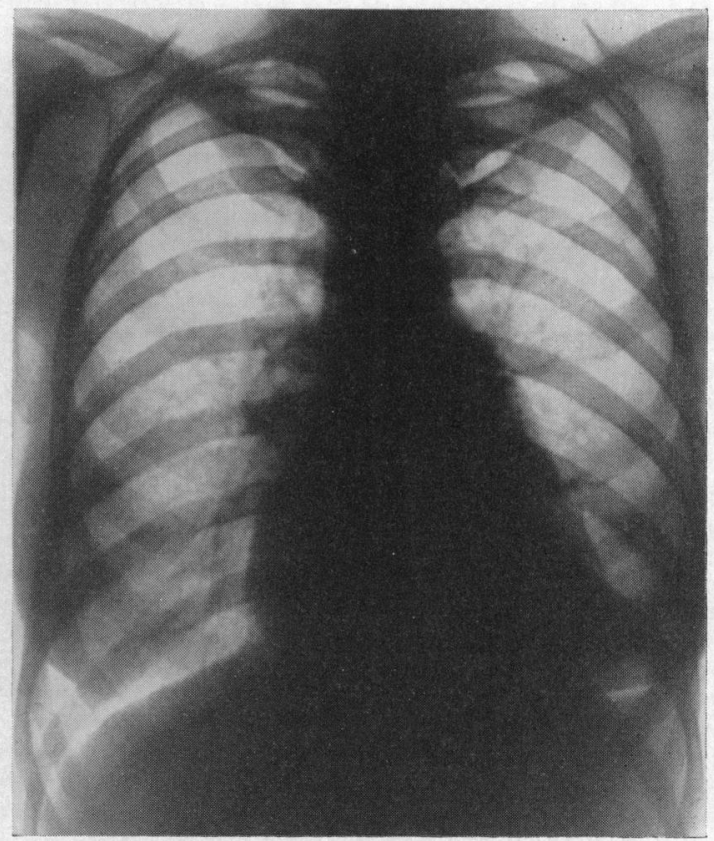

B

Fig. 5.-Postero-anterior radiograms of the same patient, (A) before, and (B) after, mitral valvotomy. Slight increase in size of right atrium after valvotomy. 
(Fig. 4), while in the remaining two, it was only slight (Fig. 5), which correlated well with the mild degree of incompetence in these two.

In the two patients with slight tricuspid incompetence before operation, the right atrial enlargement already present did not increase after mitral valvotomy with the development of increased incompetence.

Atrial fibrillation developed in the immediate post-operative period in the three patients with sinus rhythm before mitral valvotomy. In all three the onset of fibrillation preceded the development of tricuspid incompetence, since it occurred within the first ten days of operation, whereas tricuspid incompetence was never seen under a fortnight.

It was sometimes difficult to distinguish the onset of tricuspid incompetence from a post-operative pericardial effusion (Papp and Zion, 1956), for both complications may develop within the same post-operative period and both give rise to an increase in the jugular venous pressure. In the presence of a pericardial effusion the general level of the jugular venous pulse is raised, but the wave form appears normal. In tricuspid incompetence, on the other hand, the systolic $c v$ wave form is abnormal, and this, combined with the accompanying systolic pulsation of the liver, is diagnostic of the condition. Another point, which sometimes helped to distinguish the two conditions, was the frequent presence of substernal pain and pyrexia and the characteristic generalized cardiac enlargement in the radiogram, when the signs indicated pericardial effusion. Where, however, both a pericardial effusion and tricuspid incompetence developed together after operation, as happened in two patients, it was difficult to be certain of the degree of incompetence, until the effusion had subsided.

\section{Progress After Operation}

In contrast with the obvious signs of tricuspid incompetence in the neck, the general progress after valvotomy has been good and the symptoms attributable to the tricuspid lesion few. Two of the patients have now been followed for four years since operation, two for three years, one for two years, two for one year, and one for six months. All are living and with one exception are in good health and are pleased that they had the operation. They feel that their breathing has been improved and, whereas previously they were very restricted in their activities, they are now able to lead useful lives, doing light household duties. Three complain of a feeling of fulness at times beneath the left costal margin, due to hepatic congestion, and these three need regular diuretics to keep them free from œdema. All the patients are digitalized, this being necessary in seven on account of atrial fibrillation.

Only one patient has deteriorated. At operation, a supple mitral valve was split, with enlargement of its long diameter from $1 \mathrm{~cm}$. to $3 \mathrm{~cm}$., but a small regurgitant flow was felt, which was unaffected by valvotomy. There was no clinical evidence of pulmonary hypertension, the heart was moderately enlarged (Fig. 4, A) and she had never been in congestive failure. Atrial fibrillation had become established four months before operation. There was evidence of slight aortic incompetence, but none of a pre-existing tricuspid valve lesion. Following mitral valvotomy, gross tricuspid incompetence gradually developed, with an accompanying low output state, general debility and poor nutrition: in addition recurrent bronchitis became troublesome. There has been no significant change in her condition over the past four years since mitral valvotomy.

\section{MeChanism}

Two causes of post-operative tricuspid incompetence were examined, namely, general factors that might precipitate right heart failure with functional tricuspid incompetence, and local factors, . either in the form of tricuspid valvulitis from re-activation of rheumatism in the immediate post- operative period, or the unmasking of a latent tricuspid valve lesion as a result of mitral valvotomy.

Among general factors considered were inadequate splitting of the mitral valve, great generalized 
cardiac enlargement, congestive failure unrelieved by operation, severe pulmonary hypertension, and finally aortic valve lesions.

Splitting of the mitral valve had been successfully performed in all patients in this group. All, except one, had tight stenosis before operation, the long diameter of the valve measuring about $1 \mathrm{~cm}$., and the average diameter after valvotomy was about $3 \mathrm{~cm}$. The patient without tight stenosis was found to have a valve with a long diameter of $2 \mathrm{~cm}$., but splitting was specially successful in her case, and the surgeon reported a nearly normal valve with a long diameter of about $4 \mathrm{~cm}$. after operation. Only one patient had calcification of the mitral valve and in this case it was slight and confined to the contact margins of the cusps and was unlikely to have interfered with the success of valvotomy. Slight mitral incompetence was present before operation in two patients, but was never the dominant lesion: in neither of these was it increased by valvotomy. In one patient, however, mitral incompetence was produced at operation, although only of slight degree.

Great cardiac enlargement was not a feature of the group, only two of the patients showing more than the average slight to moderate enlargement seen in patients selected for mitral valvotomy in this hospital. Recurrent attacks of congestive failure were seen in only two of the patients before operation. Pulmonary hypertension of severe degree was met in only two and of a lesser degree in a third. No patient had associated aortic valve disease of sufficient degree to prejudice the success of valvotomy, slight aortic incompetence being present in two only.

There seemed, therefore, to be no general cause, common to all patients, that might have been responsible for right heart failure and accompanying functional tricuspid incompetence after mitral valvotomy.

Having largely excluded functional tricuspid incompetence as the cause of the syndrome, local organic lesions of the tricuspid valve remained to be considered. Apart from two patients, in whom a pyrexia accompanied a large pericardial effusion, none had clinical evidence of active rheumatism in the post-operative period, such as a significant pyrexia, persistently raised sedimentation rate, or painful swollen joints. In the absence, therefore, of any general signs of active rheumatism, it seemed unlikely that acute tricuspid valvulitis, developing in the immediate postoperative period, could have been the cause of the syndrome.

Unmasking of pre-existing tricuspid valve disease as a result of successful mitral valvotomy was the final possibility examined. After successful relief of tight stenosis by mitral valvotomy, the stroke output of the left ventricle is probably increased as a result of improved left ventricular filling (Dickens et al., 1957). The right ventricular stroke output is increased pari passu, and the diastolic volume of the right ventricle is enlarged to deliver this increased output. It is likely that the tricuspid ring dilates as well as the body of the ventricle in this process, and thus, a previously scarred, but competent, tricuspid valve might be rendered incompetent. The very success, therefore, of mitral valvotomy may itself unmask a previously latent tricuspid valve lesion.

Slight scarring of the tricuspid valve without clinical evidence of incompetence or stenosis is not an uncommon finding at autopsy in patients with mitral stenosis. Gross and Friedberg (1936) found microscopical evidence of rheumatic inflammation in the tricuspid valve almost as often as in the mitral valve, but noted that significant incompetence or stenosis was uncommon. Evans (1956) states that tricuspid valve disease is present in about one-fifth of patients with rheumatic heart disease, but that clinical diagnosis is possible only in about one-tenth. In the less severe cases, the anatomical damage to the valve amounts to little more than thickening of the edges of the cusps, with consequent slight reduction in their width, and in addition some shortening of the chordæ tendinex. It may well be that such a valve, although capable of functioning normally under conditions of low stroke output imposed upon it by mitral stenosis, becomes incompetent after relief of mitral stenosis, when a more normal and flexible cardiac output becomes possible. Hollman (1957) has shown that the tricuspid valve is specially prone to become incompetent owing to its tri-foliate structure.

In support of this suggestion may be cited the three patients, who had signs suggesting a minor tricuspid valve lesion before mitral valvotomy, there being evidence of slight tricuspid stenosis in 
one and of slight incompetence in the other two. Two had had a very successful mitral valvotomy, the long diameter of the valve being enlarged from 1 to $3.5 \mathrm{~cm}$. in one and from 2 to $4 \mathrm{~cm}$. in the other: in the third patient valvotomy was less complete, the final diameter of the valve measuring $2.5 \mathrm{~cm}$. All three have now developed gross tricuspid incompetence, the $c v$ wave in the jugular venous pulse being 10 to $12 \mathrm{~cm}$. above the sternal angle with the patient lying at $45^{\circ}$. Whereas before mitral valvotomy the tricuspid valve functioned nearly normally in these patients, after successful mitral valvotomy with resultant increase of the stroke output of the heart from a relatively low to a more normal level, permanent and gross tricuspid incompetence followed.

Finally, the high incidence of atrial fibrillation, in this group of patients after operation, suggests that fibrillation predisposes to the development of tricuspid incompetence. Seven of the eight patients were in atrial fibrillation after operation, five having been fibrillating before operation and two developing permanent fibrillation after it. Goodwin et al. (1957) pointed out that, in patients with tricuspid stenosis, associated tricuspid incompetence appeared to increase after the onset of fibrillation. With one exception, none of our patients had clinical evidence of tricuspid stenosis before mitral valvotomy, but it may be that rheumatic scarring of the valve without actual stenosis predisposes similarly to incompetence, when fibrillation develops. Thus, a third factor may be added to the cause of this syndrome, namely atrial fibrillation supervening in a patient with slight scarring of the tricuspid valve, following a successful mitral valvotomy.

\section{SUMMARY}

An uncommon though important complication of mitral valvotomy for mitral stenosis is described. Permanent tricuspid incompetence comes on soon after a successful mitral valvotomy, without any obvious cause for sudden right heart failure, in a patient in whom tricuspid incompetence was absent or only transient or of slight degree.

In spite of the development of tricuspid incompetence, the general progress after mitral valvotomy is favourable.

It is suggested that unmasking of a previously latent and minor tricuspid valve lesion as a result of successful mitral valvotomy is the cause of the syndrome, atrial fibrillation being a contributory factor.

I should like to thank Dr. William Evans, Dr. Wallace Brigden, Mr. Vernon Thompson, and Mr. Geoffrey Flavell for their helpful advice and encouragement in the preparation of this paper. Thanks are also due to Mr. William Dicks, Mr. Raymond Ruddick, and Miss Gwen Clarke for technical assistance.

\section{REFERENCES}

Dickens, J., Villaca, L., Woldow, A., and Goldberg, H. (1957). Brit. Heart J., 19, 419.

Evans, W. (1956). Cardiology. 2nd. ed. Butterworth, London.

Goodwin, J. F., Rab, S. M., Sinha, A. K., and Zoob, M. (1957). Brit. med. J., 2, 1383.

Gross, L., and Friedberg, C. K. (1936). Amer. J. Path., 12, 469, 855.

Hollman, A. (1957). Brit. Heart J., 19, 211.

Mounsey, J. P. D. (1957). Brit. med. J., 2, 311. (1957). Brit. Heart J., 19, 259.

Müller, O., and Shillingford, J. (1954). Brit. Heart J., 16, 195.

Papp, C., and Zion, M. M. (1956). Brit. Heart J., 18, 153. 